\title{
ANÁLISE DO SISTEMA LOGÍSTICO DE UM SUPERMERCADO NO INTERIOR DO ESTADO DE SÃO PAULO
}

\author{
Ana Paula Taveira Alves (Centro Universitário Municipal de Franca) \\ anapaulataveira5@gmail.com \\ Adriana Figueiredo de Morais Abreu (Universidade de Franca) nanafigueredo17@gmail.com \\ Paulo Renato Pakes (Universidade Federal de São Carlos) paulopakes@gmail.com
}

\section{Resumo}

Este artigo tem como objetivo analisar o sistema logístico de um supermercado localizado no interior do estado de São Paulo, de modo a caracterizar as atividades logísticas envolvidas desde a entrada até a saída de mercadorias. O presente estudo também busca analisar quais as prioridades competitivas da organização e se estão alinhadas à logística. Para isso, utilizou-se como método o estudo de caso único. Obteve-se como principal resultado que a empresa, ao desenvolver seu próprio sistema logístico, obteve mais controle e minimizou os erros e facilitou os processos de trabalho. Portanto, conclui-se a importância das plataformas logísticas serem entendidas como fatores reais e primordiais no cenário competitivo.

Palavras-Chaves: Atividades logísticas, logística empresarial, prioridades competitivas.

\section{Introdução}

A logística é considerada um conjunto de atividades e processos interligados, cujo propósito é otimizar o sistema como um todo, minimizando os custos e, consequentemente, gerando valor para o fornecedor e para o cliente (FARIA; COSTA, 2005). Vista sob uma visão processual, a logística pode ser entendida como um conjunto de atividades funcionais cíclicas ao longo do canal de suprimentos através do qual as matérias-primas são convertidas em produtos acabados e o valor é adicionado (BALLOU, 2006). Observa-se então que o objetivo é prover aos clientes os níveis de serviços requeridos, com a entrega do produto correto, no lugar exato, no momento adequado, nas condições combinadas e pelo custo certo (LAMBERT; BURDUROGLU, 2000; FARIA; COSTA, 2005).

Sabe-se que a logística é fator de sucesso imprescindível em todos os setores industriais, tendo em vista o crescimento da competitividade, sendo assim, empresas que vendem produtos de forma 
tradicional, não têm condições de obter vantagem sobre seus concorrentes sem a implantação de redes logísticas de alto desempenho (VIEIRA, 2009).

No que concerne à estratégia empresarial para guiar as operações, alguns autores propõem que existem diferentes prioridades competitivas que podem ser consideradas pelos gestores de produção (PIRES, 1995). Na visão de Slack, Chambers e Johnston (2002), a estratégia de negócios tem por objetivo guiar a empresa em relação a seus consumidores, mercados e concorrentes, além de dar sustentação à estratégia do grupo corporativo que está contida. Em consonância, identificaram cinco prioridades competitivas básicas, tais como: custo, qualidade, desempenho, flexibilidade e confiabilidade.

Quadro 1 - Prioridades Competitivas

\begin{tabular}{|l|l|}
\hline \multicolumn{1}{|c|}{ Prioridades Competitiva } & Conceito \\
\hline Custo & $\begin{array}{l}\text { Possui finalidade relativa a valor agregado; eficiência; custo } \\
\text { por hora de operação e custo médio da mesma, assim como } \\
\text { por unidades produzidas. }\end{array}$ \\
\hline Qualidade & $\begin{array}{l}\text { Fatores operacionais que limitam (número unitário de } \\
\text { defeitos produzidos; \% ou ppm de refugo e retrabalhos; } \\
\text { medição de índice de satisfação dos consumidores);Devem } \\
\text { ser adequados conforme as expectativas do } \\
\text { clientes/consumidores . }\end{array}$ \\
\hline Desempenho & $\begin{array}{l}\text { Influenciado principalmente pelas necessidades dos } \\
\text { consumidores e suas preferências. Garante confiabilidade } \\
\text { nos prazos e oferece prontamente peças de reposição para } \\
\text { serviços de assistência. }\end{array}$ \\
\hline Clexibilidade & $\begin{array}{l}\text { Tempo necessário para mudança de programação da } \\
\text { produção; especificaçães de entrega e prazos solicitados por } \\
\text { clientes assim como a capacidade de adaptação a mudanças } \\
\text { dos prazos. }\end{array}$ \\
\hline $\begin{array}{l}\text { Aderência da produção e à entrega na programação prevista, } \\
\text { assim como a previsão de possíveis atrasos e desvio médio } \\
\text { do tempo real em relação a promessa de entrega. É a } \\
\text { probabilidade de que um sistema dê a resposta esperada } \\
\text { durante um período pré-determinado submetido a a } \\
\text { determinadas condições. }\end{array}$ \\
\hline
\end{tabular}

Fonte: Elaborado a partir de Slack, Chambers e Johnston (2009)

Como se vê, tratam de um conjunto consistente de critérios que a empresa tem de valorizar para aumentar a sua competitividade e, por conseguinte, a sua participação no mercado e a sua lucratividade, de forma que aproveite seus recursos, capacidades e oportunidades de mercado. 
Neste contexto, esta pesquisa tem por objetivo analisar o sistema logístico de um supermercado, localizado no interior do estado de São Paulo, de modo a identificar as atividades logísticas envolvidas em todo o processo, abrangendo desde a chegada até a saída das mercadorias, como também, discorrer sobre as prioridades competitivas presentes e sua relação com a logística, levando-se em consideração a importância do funcionamento adequado desse sistema para o desempenho da cadeia de suprimentos, tendo em vista a necessidade de eficácia operacional e competitiva aliado às necessidades dos consumidores.

\section{Referencial teórico}

\subsection{Atividades logísticas}

De acordo com Buller (2012) a logística empresarial nada mais é do que a quebra de fronteiras e um avanço tecnológico que possibilita englobar horizontes amplos e externos às organizações, abrangendo fornecedores e clientes que buscam por um mesmo propósito. Para um maior entendimento adotamos a visão proposta por Ballou (2006) sobre o objetivo da logística empresarial, sendo está retratada como a busca por desenvolver um mix de atividades a atender as necessidades do cliente providenciando bens ou serviços corretos, no lugar certo, no tempo exato e na condição desejada ao menor custo possível, com retorno de investimento no menor tempo. Para conseguir atingir esse objetivo é necessário administrar adequadamente as atividades da logística.

Para isso, Ballou (2006) divide as atividades logísticas em duas categorias, sendo a primeira categoria a das atividades chaves ou principais, que são elas: serviços ao cliente; transporte; gerencia de estoque e fluxos de informação e processamento de pedidos. A segunda categoria são as atividades de suporte que podem possuir a função de contribuintes para a realização das atividades principais, são elas: armazenagem; manuseio dos materiais; compras; embalagem; cooperação com produção/operações e manutenção de informações.

\subsection{Atividades chaves}

As atividades chaves representam em suma a parte majoritária dos custos e são essenciais na coordenação e eficácia na conclusão da tarefa logística, além disso fazem parte do circuito crítico do canal de distribuição física logístico (BALLOU, 2006). 
As atividades chaves, como citado anteriormente, possuem decisões diretamente relacionadas a ela.

Quadro 2 - Atividades chaves

\begin{tabular}{|c|c|c|}
\hline Transporte & Manutenção de Estoques & Processamento de Pedidos \\
\hline $\begin{array}{l}\text { Seleção da modalidade e } \\
\text { serviços de transporte; }\end{array}$ & $\begin{array}{l}\text { Política de estocagem de } \\
\text { matérias primas e produtos } \\
\text { finalizados; }\end{array}$ & $\begin{array}{l}\text { Interface entre compras de } \\
\text { novos produtos e estoque; }\end{array}$ \\
\hline Consolidação de fretes; & $\begin{array}{l}\text { Previsão a curto prazo de } \\
\text { vendas; }\end{array}$ & $\begin{array}{l}\text { Método de transmissão de } \\
\text { pedidos; }\end{array}$ \\
\hline Determinar roteiros; & $\begin{array}{l}\text { Variedade de produtos em } \\
\text { estoque; }\end{array}$ & Regras sobre os pedidos. \\
\hline Selecionar equipamentos & $\begin{array}{l}\text { Número, localidade e } \\
\text { tamanho dos pontos de } \\
\text { estocagem; }\end{array}$ & $\begin{array}{l}\text { Interfere diretamente no custo } \\
\text { e nível de serviço ao cliente; }\end{array}$ \\
\hline Programação de veículos; & $\begin{array}{l}\text { Estratégia empurrada e } \\
\text { puxada (Just-in-time); }\end{array}$ & Custo relativamente baixo; \\
\hline $\begin{array}{l}\text { Processamento } \\
\text { reclamações; }\end{array}$ & $\begin{array}{l}\text { Agrega valor de tempo ao } \\
\text { produto; }\end{array}$ & $\begin{array}{l}\text { Necessário o investimento de } \\
\text { tecnologia; }\end{array}$ \\
\hline Auditoria de frete. & $\begin{array}{l}\text { Permite que os produtos } \\
\text { sempre estejam disponíveis } \\
\text { ao cliente. }\end{array}$ & $\begin{array}{l}\text { Mantém os processos } \\
\text { logísticos abastecidos de } \\
\text { informações necessárias para o } \\
\text { planejamento. }\end{array}$ \\
\hline
\end{tabular}

Fonte: Adaptado de Ballou, (2006, p. 31-32).

Além disso, estas atividades logísticas podem ser colocadas em perspectiva notando-se sua importância naquilo que pode ser chamado de "ciclo crítico de atividades logísticas". Como mostrado na Figura 1, o tempo requerido para um cliente receber um pedido depende do tempo necessário para entregar o pedido. Como o resultado final de qualquer operação logística é prover serviço por conseguir mercadorias para os clientes quando e onde eles quiserem, estas três atividades são centrais para cumprir esta missão.

Figura 1 - Relação entre as três atividades logísticas primárias para atender os clientes - o "ciclo crítico" 


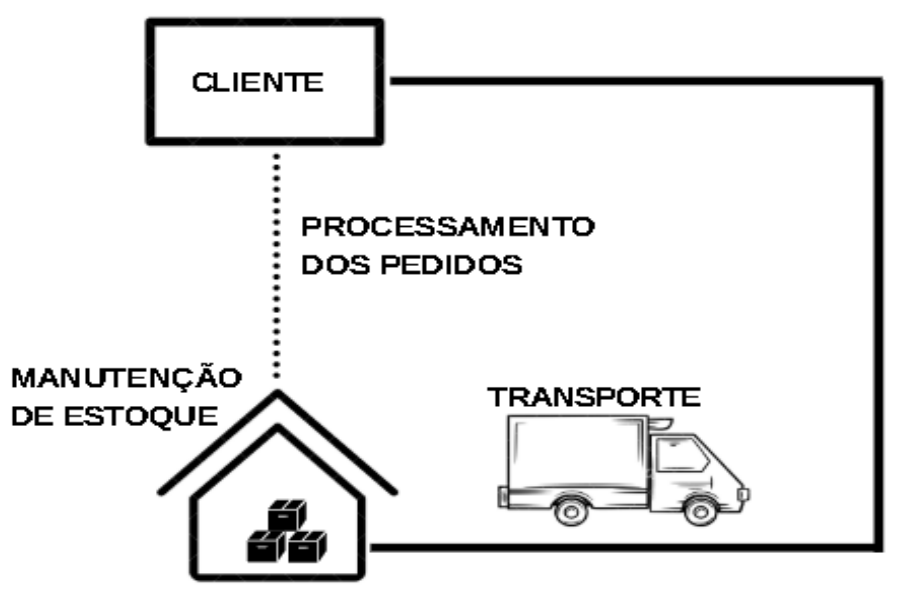

Fonte: Ballou, (2006, p. 32).

\subsection{Atividades de suporte}

Segundo Ballou (2006) as atividades de suporte podem ser tão críticas quanto as atividades chave, embora em determinadas circunstâncias podem ser consideradas como apoio ou contribuintes para a realização da missão logística. Essas atividades são de suma importância sendo indispensáveis no processo logístico, pois, contribuem para a disponibilidade e a condição física de bens e serviços para que os processos fluam e seja atendido o objetivo da redução de distâncias entre a demanda e a produção, para a satisfação dos clientes.

Quadro 3 - Atividades de suporte

\begin{tabular}{|c|c|c|c|}
\hline Armazenagem & Manuseio de Materiais & Embalagem & Obtenção/Suprimento \\
\hline $\begin{array}{l}\text { Administração do } \\
\text { espaço; }\end{array}$ & $\begin{array}{l}\text { Triagem } \\
\text { equipamentos; }\end{array}$ & Manuseio; & $\begin{array}{l}\text { Seleção do fornecedor de } \\
\text { suprimentos; }\end{array}$ \\
\hline Layout do local; & $\begin{array}{l}\text { Normas e regras para } \\
\text { mutação } \\
\text { equipamentos; }\end{array}$ & Estocagem; & Instante da compra; \\
\hline $\begin{array}{l}\text { Configurações } \\
\text { armazém; }\end{array}$ & $\begin{array}{l}\text { Metodologia para } \\
\text { separação de pedidos; }\end{array}$ & $\begin{array}{l}\text { Proteção à perdas e } \\
\text { possíveis danos; }\end{array}$ & Quantidade; \\
\hline Posição de estoque; & $\begin{array}{l}\text { Alocação e recuperação } \\
\text { de materiais; }\end{array}$ & $\begin{array}{lr}\text { Utilizadas } & \text { para } \\
\text { movimentar bens sem } \\
\text { que } & \text { sejam } \\
\text { danificados; } & \end{array}$ & $\begin{array}{l}\text { Deixa o produto } \\
\text { disponível para o sistema } \\
\text { logístico; }\end{array}$ \\
\hline $\begin{array}{l}\text { Administração } \\
\text { espaço. }\end{array}$ & $\begin{array}{l}\text { Triagem } \\
\text { equipamentos. }\end{array}$ & $\begin{array}{l}\text { As embalagens } \\
\text { podem ser primárias, } \\
\text { secundárias, } \\
\text { terciárias e } \\
\text { quaternárias. }\end{array}$ & $\begin{array}{l}\text { Envolve detalhes de } \\
\text { procedimento tais como } \\
\text { negociação de preços e } \\
\text { avaliação de vendedores. }\end{array}$ \\
\hline
\end{tabular}

Fonte: Adaptado de Ballou, (2006, p. 32). 


\section{Método}

No presente trabalho, optou-se por utilizar o método de estudo de caso, segundo Yin (2010), o estudo de caso representa uma investigação empírica e compreende um método abrangente, com a lógica do planejamento, da coleta e da análise de dados. Em sua obra, Yin classifica o estudo de caso quanto ao tipo, que pode ser: descritivo, explanatório e exploratório. Este estudo classificase como sendo descritivo, uma vez que o modelo descritivo possibilita, ao investigador, a descrição de fenômenos contemporâneos dentro de seu contexto real, enquanto o explanatório foca em verificar proposições teóricas (hipóteses) já estabelecidas e articulá-las com teorias já existentes e o exploratório permite ao investigador elencar elementos que the permitam diagnosticar um caso com perspectivas de generalização naturalística (YIN, 2005; YIN, 2010).

Primeiramente a pesquisa foi realizada através de um levantamento bibliográfico, assim, houve a definição da estrutura teórica, onde foram realizadas pesquisas nos Portais Google e Capes, com intuito de selecionar trabalhos de autores renomados que tratavam das atividades logísticas, sintetizando estas informações será realizado um estudo de caso. Segundo Santos (2006) a Revisão Bibliográfica faz parte do projeto de pesquisa, mostrando todos os aportes científicos e literários sobre um determinado tema. Posteriormente foram definidas a organização empresarial que seria alvo do estudo e a estruturação do roteiro de entrevista.

Para a coleta de dados foram realizadas visitas in loco, em um supermercado situado no interior de São Paulo, bem como a gravação de entrevistas informais com o gestor da organização, com duração de aproximadamente uma hora, para assim, obter dados sobre as atividades logísticas existentes no estabelecimento. Em seguida os dados foram analisados por meio de uma comparação com o levantamento bibliográfico, onde observa-se como é a teoria e como aplica-se a prática, desse modo foi discorrido sobre as atividades primárias e de suporte que a organização possui e estas atividades foram relacionadas com as vantagens competitivas, evidenciando sua importância. Após, foram compilados por meio deste artigo, conforme apresentado na próxima seção, vale ressaltar que a pesquisa possuiu um intervalo de quatro meses para que todos os elementos citados fossem realizados.

\section{Estudo de caso}




\subsection{A empresa}

O estudo de caso foi realizado em uma loja de uma rede varejista, localizada no interior do estado de São Paulo. Primeiramente a loja iniciou-se sendo uma pequena panificadora localizada em uma cidade mineira. Atualmente, a rede conta com 18 lojas e mais de 2200 colaboradores, sendo que 88 destes fazem parte da loja analisada.

A empresa possui a visão de garantir sempre a melhor experiência de compra, primar pela satisfação e também, ser cada vez mais um referencial de excelência, confiança e economia no atacado varejo. Dessa forma, para que consigam atingi-la e aumentar a eficiência de suas atividades em si, ela conta com um sistema em sua plataforma logística, objeto de estudo desta pesquisa.

A rede de supermercados possui seu próprio centro de distribuição, o qual, situa-se em uma cidade mineira, localizada à $107 \mathrm{~km}$ da cidade onde está estabelecido o Supermercado em que as atividades foram identificadas, sendo elas: transporte, manutenção de estoques, processamento de pedidos, armazenagem, manuseio de materiais, embalagem e obtenção/suprimento. Na Figura 2 é possível identificar tais atividades.

Figura 2 - Atividades logísticas envolvidas no Supermercado

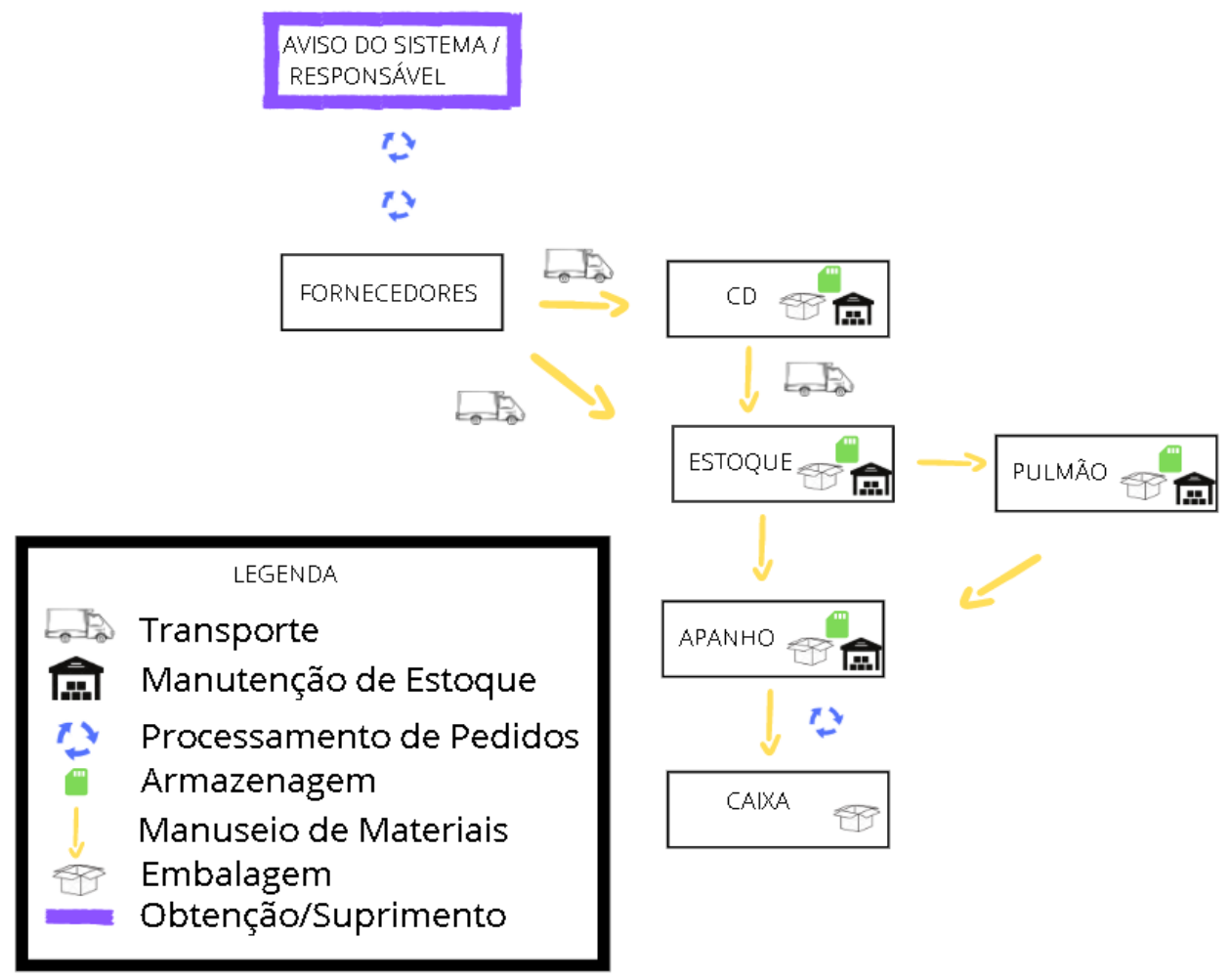

Fonte: Autoria própria 


\subsection{Atividades primárias}

O transporte dos produtos é realizado por meio de caminhões da empresa e de fornecedores. Os caminhões da empresa são responsáveis por transportar os produtos para o centro de distribuição (CD) e também de levá-los para as lojas que necessitam. Há também alguns caminhões de fornecedores que levam de forma direta os produtos para as lojas.

A manutenção de estoque é realizada por meio do sistema de informação, uma vez que todos os produtos são cadastrados e possuem suas informações atualizadas constantemente, como por exemplo, as quantidades que constam na área de vendas e no estoque. Dessa forma, se estiver produtos em falta na área de vendas, o sistema irá avisar no momento em que for realizar o seu endereçamento.

Há dois tipos de endereçamento, o pulmão, que é a parte superior das estantes onde os produtos são armazenados na loja e o apanho, que é a área de vendas, partes inferiores da estante. Dessa forma, a loja possui estoque, estoque intermediário e área de vendas.

Para realizar o abastecimento, também há duas formas: a) via coletor, de modo que quando o seu código de barras é lido, ele indica as quantidades existentes no pulmão, no apanho e a capacidade de armazenamento em cada uma delas e b) pelo sistema, que ocorre de forma automática e é realizado com maior frequência durante as madrugadas, uma vez que não há fluxo de clientes.

Conforme os produtos são vendidos, eles devem ser atualizados no sistema, assim, indicará de forma atualizada a capacidade momentânea e a necessidade de reabastecimento. Os produtos descem do pulmão para o apanho, de modo que o pulmão deve sempre continuar com sua capacidade máxima sendo utilizada.

Como o sistema conta com operação humana, consequentemente possui falhas, desse modo, ainda são realizadas as remontagens, ato de agrupar mercadorias com a finalidade de obter espaço na área de vendas, no momento que o agrupamento é realizado, deverá ser feito uma conferência em todos os paletes, verificando se estão corretos e atualizando as informações.O processamento de pedidos é realizado de duas maneiras: a) produtos que são encaminhados a loja, estes, quando chegam ao $\mathrm{CD}$, há um responsável que analisa o sistema, verificando quais produtos cada loja necessita e assim, os encaminha e b) feitos no momento em que o cliente realiza o pagamento, tanto no caixa, pelas vendas físicas, tanto nas vendas realizadas pelo setor de televendas, onde, a 
vendedora fará o pedido que o cliente deseja, a roteirização, ou seja, incluir os endereços das mercadorias no sistema para que sejam finalizados e reabastecidos.

Após o pedido realizado é emitido a fatura e caso o pagamento não seja efetuado, há o cancelamento da compra. Evidencia-se que todos os códigos são coletados através de um coletor e inseridos no sistema para que assim a loja possua um controle de todo o fluxo de entrada e saída.

\subsection{Atividades de suporte}

A empresa possui um centro de distribuição (CD) e, ainda, há um setor para armazenagem na loja, todos os produtos que chegam pelos caminhões possuem uma folha que indica toda a mercadoria que consta em cada palete e possui também uma etiqueta com um código de barras para conferência, desse modo, tudo o que entra na loja já é alocado ao sistema no momento em que a nota fiscal é gerada.

Assim que os produtos são retirados dos caminhões, um responsável inicia o processo de separação da carga, uma vez que os paletes são mistos, ou seja, não possui apenas produtos fechados, nesse processo, deve-se alocar os produtos correspondente, pois, depois serão levados a um corredor específico dentro da loja. Após a separação, cada código de barras deve ser lido pelo sistema, com a finalidade de indicar a quantidade de cada produto em cada palete, para ser realizado uma conferência com a nota fiscal. Feito isto, um operador de empilhadeira irá ser acionado para ler o código de barras que consta em cada palete e então realizar o endereçamento das mercadorias. Já os produtos que não passam pelo $\mathrm{CD}$, irão possuir outro processo, que somente será gerado a etiqueta uma vez e então feito o endereçamento.

Para o processo de endereçamento ser possível, há etiquetas em todas as estantes da loja, assim, fará com que a loja funcione como uma cidade. Por exemplo, cada etiqueta possui três números, o primeiro número corresponde a rua, o segundo ao prédio e o terceiro ao apartamento. Portanto, como indicado na Figura 3, esta será a rua 12, prédio 13 e apartamento 0, 1, 2 e 3. Evidencia-se que o apartamento 0 corresponde ao apanho e o restante, ao pulmão, onde, cada etiqueta será referente a um palete posicionado na estante.

Figura 3 - Etiquetas de endereçamento 

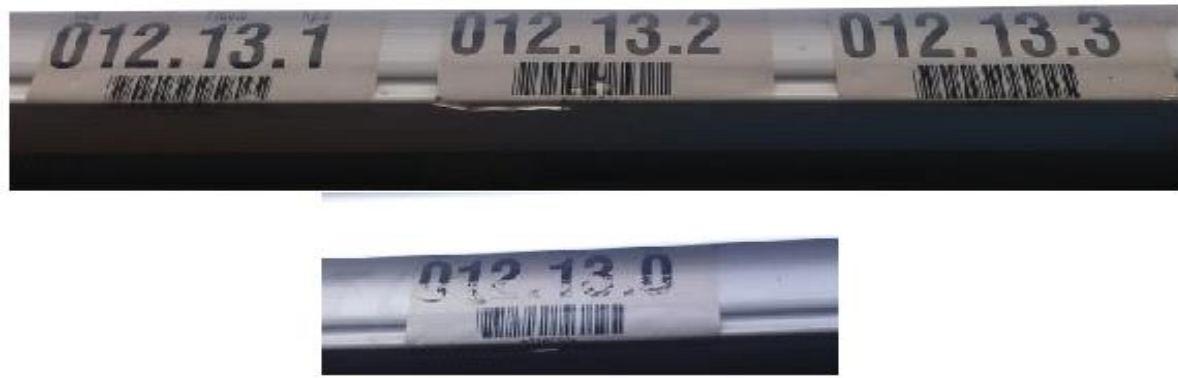

Fonte: Pesquisa de campo

O manuseio de materiais ocorre principalmente em consonância com a armazenagem, assim que as mercadorias chegam nos caminhões, são alocadas ao estoque por meio de empilhadeiras, depois de feito toda a conferência e endereçamento, novamente por meio de empilhadeiras, são alocadas próximo a entrada que dá para a loja, onde irão aguardar para serem levadas ao apanho ou pulmão, ainda, por meio de empilhadeiras.

Também é realizado o manuseio de materiais pelos clientes, o qual, se dá por meio de carrinhos de compras até o caixa.

As mercadorias chegam à loja embaladas em caixas que são colocadas em paletes, assim que descarregadas dos caminhões, conferidas e endereçadas, são retiradas das caixas os produtos que irão para o apanho, já os que são direcionados ao pulmão, permaneceram nas caixas e em seus respectivos paletes e quando necessário irem para o apanho, é realizado o mesmo processo, ou seja, são retirados das caixas.

Assim que as mercadorias são vendidas e passam pelo caixa, são alojadas em sacolas plásticas ou caixas, dependendo da quantidade de produtos e também da escolha do cliente.

A obtenção/suprimento das mercadorias de todas as lojas é realizada na matriz e levadas ao CD, sendo assim, buscam realizar uma única compra, o que faz com que obtenham preços mais acessíveis, já que contam com uma demanda maior, desse modo, a matriz realiza pesquisa com fornecedores e também acordos comerciais para se caso algum produto vencer a validade enquanto estiver na loja. Para a rede, o único jeito de obter sucesso nas vendas é realizando uma compra correta, com bons preços e quantidades conformes.

Há também, a realização de pedidos de compras de alguns produtos pelo responsável do setor específico em cada loja, como por exemplo, pães industrializados, por possuírem validade curta, desse modo, a compra é feita para que o estoque seja mantido por 15 dias, para assim, evitar perdas. 


\subsection{Relação entre as atividades de logística e as prioridades competitivas}

Considerando as prioridades competitivas apontadas pelo entrevistado como norteadoras da atuação da empresa, pode-se elencar distintamente o que é praticado em cada uma:

a) custo: é realizado uma compra única pelo CD para todas as lojas da rede, consequentemente, aumenta o poder de negociação;

b) qualidade: a vistoria continua efetuada nos produtos, tanto no momento que chegam à loja, onde o seu estado é analisado, quanto para verificar sua validade;

c) desempenho: o fato de estar sempre com o sistema atualizado permite verificar se a loja possui a quantidade necessária de todas as mercadorias, pulmão/apanho, sendo assim, é feito o reabastecimento e pedido de compra quando necessário, dessa forma, os clientes irão ter o que desejam no tempo certo e no momento exato;

d) flexibilidade: podemos citar os acordos feitos com fornecedores e as promoções feitas pela própria loja, para o caso de produtos que atingem a validade;

e) confiabilidade: pode-se englobar tudo já citado nas prioridades anteriores e também o uso do sistema, em razão de garantir que o que consta no sistema, consta também na loja, assim, tudo será realizado conforme o planejado.

Dessa forma, é possível observar a consonância de práticas evidenciadas na logística com as cinco prioridades competitivas, visto que: a competitividade irá sustentar-se na eficácia do sistema logístico, pois atua para que tudo funcione de forma correta, tendo o propósito de garantir um melhor desempenho da loja para com o cliente, conciliando numa satisfação para o mesmo, e assim, gera-se um lucro maior para o estabelecimento, em sintonia, uma maior competitividade no mercado em relação a concorrência, sendo notória a importância das atividades logísticas aliadas às prioridades competitivas em um supermercado.

\section{Conclusão}

Com a pesquisa foi possível observar como está aplicada a logística em um supermercado, cujo intuito foi observar e descrever as atividades logísticas em uma loja específica de uma grande rede de supermercados. 
Verificou-se que a rede possui um sistema específico que auxilia e facilita na aplicação e funcionamento da logística. Ainda, foi evidenciado que as falhas do sistema se dão principalmente por operações humanas, seja por cansaço ou esquecimento dos funcionários, de maneira que esse descuido resulte na não atualização de informações no sistema. Diante disso, a empresa conta com maneiras corretivas para tentar solucionar essas falhas, como frequentes vistorias e conferências nos estoques, no apanho e no pulmão da loja.

Nota-se, também, a importância da logística na competitividade, ou seja, a plataformas logística permite alcançar posições competitivas, uma vez que graças a ela, o desempenho se manter em bom funcionamento, já que os produtos serão dispostos em lugares determinados, de modo que sempre saibam a sua localização, a quantidade de mercadorias presentes na loja e no estoque, de modo a disponibilizar a quantidade necessária na loja, de modo a facilitar o cálculo da demanda. Destarte, a demora para localizar o produto que o cliente deseja, assim como as chances de não o possuir na loja, será menor. Em consequência, aumentará a satisfação do cliente e além do mais, o número de vendas e fidelização de clientes, portanto, terá resultados positivos no que se refere a competitividade empresarial.

Sugere-se à organização a implantação do sistema em todas as lojas da rede, sendo que atualmente apenas 3 destas possuem-no implantado. Do mesmo modo, sugere-se que seja realizado adaptações no mesmo, para assim, tornar efetivo sua implantação no setor de frios, visto que, por trabalhar com caixas fechadas e mercadorias fracionadas, o sistema logístico deste setor possui seu controle ainda feito manualmente e de forma aleatória.

Como estudos futuros, sugere-se a realização de pesquisa semelhante em outras redes do varejo, no intuito de verificar se existem padrões ou particularidades nos sistemas logísticos nacionais. Sugere-se também a realização de pesquisas que permitam compreender as inovações nos processos logísticos do varejo que permitem incrementar a satisfação dos clientes.

\section{REFERÊNCIAS}

BALLOU, Ronald. H. Gerenciamento da cadeia de suprimentos: Planejamento, organização e logística empresarial. 5. ed. São Paulo: Bookman, 2006.

BALLOU, Ronald. H. Logística empresarial: transportes, administração de materiais e distribuição física. São Paulo: Atlas, 1993. 
BOUDOUIN, Daniel. Logística-Território-Desenvolvimento: O caso europeu. I Seminário Internacional: Logística, Transportes e Desenvolvimento. Ceará: UFC/CT/DET, 1996, p. 103-111.

BULLER, Luz Selene. Logística Empresarial. Curitiba: IESDE, 2012.

DIAS, João Carlos Quaresma. Logística Global e Macrologística. 1. ed. Lisboa: Edições Sílabo, 2005.

FARIA, Ana Cristina; COSTA, Maria de Fátima Gameiro. Gestão de custos logísticos. $1^{\mathrm{a}} \mathrm{ed}$. São Paulo: Atlas, 2005.

GODOY, Arlida Schmidt. Introdução a pesquisa qualitativa e suas possibilidades. Revista de Administração de Empresas. São Paulo, v. 35, n. 2, p. 57-63, Mar./Abr. 1995.

LAMBERT, Douglas.; BURDUROGLU, Renan. Measuring and selling the value of logistics. International. Journal of Logistics Management, v. 11, n. 1, 2000.

MARTINS, G. Petrônio; LAUGENI F. Pietro. Administração da Produção. São Paulo: Saraiva, 2012, p. 227.

MINAYO, Maria Cecília de Souza. Pesquisa Social: teoria, método e criatividade. Petrópolis: Vozes, 1994.

PIRES, Sílvio RI. Gestão estratégica da produção. Piracicaba: Unimep, 1995.

SANTOS, Vanice dos; CANDELORO, Rosana J. Trabalhos acadêmicos: uma orientação para a pesquisa e normas técnicas. Porto Alegre: AGE, p. 73, 2006.

SILVA, Edna Lúcia de; MENEZES, Estera Muszkat. Metodologia da pesquisa e elaboração de dissertação. 4 ed. Florianópolis: UFSC, 2005.

TOLEDO, José Calos. Qualidade: Gestão e Métodos. Rio de Janeiro: Gen, 2014, p. 159-161

VIEIRA, Darli Rodrigues. Análise e projetos de redes logísticas. 2. São Paulo Saraiva 2009.

YIN, R.K. Estudo de caso: planejamento e métodos. 3. ed. Porto Alegre: Bookman, 2005.

YIN, R. K. Estudo de caso: planejamento e métodos. 4. ed. Porto Alegre: Bookman, 2010. 